\title{
Caracterização genética da raça bovina Crioulo Lageano por marcadores moleculares RAPD(1)
}

\author{
Álvaro Spritze ${ }^{(2)}$, Andréa Alves de Egito(3), Arthur da Silva Mariante ${ }^{(3)}$ e Concepta McManus ${ }^{(2)}$
}

\begin{abstract}
Resumo - O objetivo deste trabalho foi a caracterização genética da raça bovina Crioulo Lageano por marcadores RAPD em comparação com as raças Holandesa e Nelore. Foram selecionados 43 primers, que geraram 77 bandas polimórficas. Os animais foram distribuídos em cinco subgrupos de Crioulo Lageano (I a V), e um subgrupo em cada uma das raças Holandesa (VI) e Nelore (VII). A maior parte da variância genética total (65,05\%) foi causada pela diferença de indivíduos dentro dos grupos, e o restante pelas diferenças entre grupos. A análise conjunta dos grupos I a V apresentou variabilidade genética entre grupos de 25,28\% e dentro dos grupos de 74,72\%. A diversidade gênica vem se mantendo ao longo das gerações no núcleo de conservação do Crioulo Lageano. A raça Holandesa apresentou a menor diversidade gênica $(0,1204)$, e a Crioulo Lageano a maior $(0,3154)$. A maior distância genética $(0,3747)$ foi entre as raças Nelore e Holandesa. Os grupos de Crioulo Lageano apresentaram diferenças entre si e apenas alguns indivíduos de cada grupo posicionaram-se junto a outros grupos. A técnica RAPD é capaz de estimar a distância genética entre raças ou populações e de auxiliar na escolha de indivíduos, visando aos trabalhos de conservação de recursos genéticos.
\end{abstract}

Termos para indexação: Bos taurus, Bos indicus, bovino, marcador genético, variação genética.

\section{Genetic characterization of Criollo Lageano cattle by RAPD markers}

\begin{abstract}
The objective of this study was to characterize genetically the Crioulo Lageano cattle breed, using RAPD markers and compare it to the Holstein and Nelore breeds. Forty three primers were selected, and they generated 77 polymorphic bands. Seven groups were studied: 5 subgroups of Crioulo Lageano (I to V) and one each Holstein (VI) and Nellore (VII). Using all groups, the greater part of the genetic variance (65.05\%) was due to differences within groups and the rest due to differences between groups. Using five Crioulo Lageano groups (I to V) the results showed $25.28 \%$ variation between groups and $74.72 \%$ within groups. Genetic diversity has been maintained throughout the generations in this conservation nucleus. The Holstein breed presented the lowest genetic diversity (0.1204) while the Crioulo Lageano herd presented the highest (0.3154). The observed genetic differences were highest between Nellore and Holstein breeds (0.3747), as expected. In general, the Crioulo Lageano groups formed distinct groups and only a few animals from one group were positioned within another group. The RAPD marker technique is adequate to estimate genetic distances between breeds and populations, as well as for use in the choice of individuals for breeding within populations, for conservation of genetic resources.
\end{abstract}

Index terms: Bos taurus, Bos indicus, bovines, genetic markers, genetic variation.

(1) Aceito para publicação em 26 de agosto de 2003.

(2) Universidade de Brasília, Faculdade de Agronomia e Medicina Veterinária, Caixa Postal 04508, CEP 70910-900 Brasília, DF. E-mail: spritze1@bol.com.br, concepta@unb.br

(3) Embrapa-Centro Nacional de Pesquisa de Recursos Genéticos e Biotecnologia, Caixa Postal 02372, CEP 70770-900 Brasília, DF. E-mail: egito@cenargen.embrapa.br, mariante@cenargen.embrapa.br

\section{Introdução}

No Brasil, o primeiro rebanho de bovinos, trazido por colonizadores, foi desembarcado em São Vicente no ano de 1534 (Lima et al., 1990). Depois chegaram mais bovinos na costa de Pernambuco e posteriormente na Bahia (Mariante \& Cavalcante, 2000). De São Vicente partiram grupos de bovinos, levados por 
colonizadores, para os campos sulinos, para Goiás, para o Vale de São Francisco (Minas e Bahia) e chegaram até os campos do Piauí e Ceará. Os bovinos desembarcados em Pernambuco e Bahia migraram para os sertões nordestinos, norte de Minas, oeste da Bahia, encontrando rebanhos originários de São Vicente (Primo, 1993).

Os três núcleos - São Vicente ao sul, Salvador ao centro e Recife, ao norte - se constituíram nas zonas importadoras de gado de origem portuguesa, que se reproduzia livremente, sem a interferência do homem (Mariante \& Cavalcante, 2000). Quase todas as raças crioulas locais tiveram como ancestrais os bovinos de Portugal, a Barrosã, a Mirandesa, a Minhota, a Alentejana e a Arouquesa (Mariante \& Cavalcante, 2000). Exposto a um processo de seleção natural durante várias gerações, o gado crioulo adaptou-se às condições locais e desenvolveu características que o permitiram sobreviver a uma oferta de alimentos geralmente pobre em nutrientes.

A origem do Gado Crioulo na América Latina, possivelmente, é dos antigos bovinos Hamíticos, caracterizados por chifres longos, domesticados no Egito há aproximadamente 4000 anos a.C., e introduzidos no sul da Espanha procedentes da África do Norte. A introdução de bovinos no Rio Grande do Sul, de acordo com Araújo (1990), foi realizada pelos jesuítas, com o propósito de abastecer os povos das Missões. Posteriormente, com a invasão das Missões pelos Bandeirantes, os bovinos capturados tinham por destino a região de Franca, SP, de onde surgiu a denominação de bovino Franqueiro. Diversos exemplares foram posteriormente transferidos para várias regiões do Brasil, onde foram cruzados com rebanhos lá existentes, formando as raças Curraleiro, Franqueiro, Junqueira, Mocho Nacional, Caracu, Pantaneira. Supõe-se que muitos animais tenham se extraviado das tropas ao longo do caminho, sendo que na região do Planalto Catarinense embrenharamse nas matas e, com o tempo, passaram a formar rebanhos nos campos de Lages. Com a colonização do Planalto Catarinense, os colonos trouxeram o gado Franqueiro, que, provavelmente, cruzou com bovinos ali existentes, originando o gado conhecido como Crioulo Lageano, que até o início do século passado era a raça predominante nos campos de Lages.
O bovino Crioulo Lageano foi, por longo tempo, o principal esteio da bovinocultura das regiões fisiográficas dos Campos de Cima da Serra no Rio Grande do Sul e do Planalto Catarinense (Mariante \& Cavalcante, 2000). A partir do final do século passado, esses bovinos passaram a ser cruzados com animais de raças européias e zebuínas. Admite-se que os bons resultados obtidos com os cruzamentos favoreceram as importações de reprodutores de outras raças, causando o desaparecimento quase que total dos bovinos Crioulos. Atualmente, a população desses bovinos encontra-se reduzida a um efetivo que não ultrapassa 500 animais, e mais de $80 \%$ da população pertence a um só criador. Trabalhos de pesquisa desenvolvidos pela Embrapa-Centro Nacional de Pesquisa de Recursos Genéticos e Biotecnologia e pela Universidade Federal de Santa Catarina, em colaboração com alguns criadores particulares, evidenciaram vantagens na exploração da raça Crioulo Lageano, não só como raça pura como também em cruzamentos, nas condições de criação extensivas do Planalto Sul-brasileiro (Mariante \& Trovo, 1989).

O bovino Crioulo Lageano, criado na Fazenda Canoas, localizada no Município de Ponte Alta, próximo a Lages, SC, extremamente adaptado à região. É rústico, com porte avantajado, maturidade sexual tardia e alta prolificidade. Apresenta mais de 40 tipos de pelagens diferentes, e a predominante é a africana, com lombo e barriga brancos e manchas vermelhas ou pretas no costilhar, e pêlos vermelhos ou pretos circundando os olhos. Alguns animais apresentam traços de zebu, enquanto outros de Franqueiro ou de gado africano (Payne, 1970).

A caracterização genética é importante para os programas de conservação de recursos genéticos animais, pois avalia a distância entre as populações em estudo e pode auxiliar na escolha dos animais a serem utilizados na conservação ex situ e in situ, mediante a estimativa de índices de similaridade entre os indivíduos analisados. Além disso, possibilita a indicação de acasalamentos ou cruzamentos que favorecerão a manutenção da máxima variabilidade genética e evita esforços na manutenção de amostras que geneticamente seriam similares (Egito et al., 2001). 
O objetivo deste trabalho foi a caracterização genética da raça bovina Crioulo Lageano, por marcadores moleculares RAPD e a comparação com as raças Holandesa e Nelore.

\section{Material e Métodos}

Foi estudado o rebanho de bovinos da raça Crioulo Lageano (BCL), criado na Fazenda Canoas, Município de Lages, SC. Como esta raça tem origem taurina, foram incluídas, neste estudo, a raça Holandesa (Bos taurus) como controle e Nelore (Bos indicus) como outgroup.

A região apresenta temperatura média anual de $16,05^{\circ} \mathrm{C}$

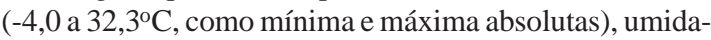
de relativa do ar média de 79,95\%, precipitação mensal média de 154,45 mm, precipitação máxima em 24 horas de 114,45 mm e média mensal dos dias com chuva de 11,97.

O clima subtropical, com florestas de pinhais e campos limpos, compõe a paisagem local (Mariante \& Cavalcante, 2000). A oferta de pastagem diminui por ocasião do inverno, por causa das geadas e, eventualmente, da neve. Embora a ocorrência de geadas concentre-se no outono, inverno e primavera, também é possível no verão. Em relação às pastagens naturais, as regiões do subtrópico brasileiro apresentam cerca de 800 espécies de gramíneas e mais de 200 espécies de leguminosas (Moraes et al., 1995). As pastagens cultivadas e o melhoramento dos campos nativos nos Campos de Lages são ainda incipientes, e a pecuária local está alicerçada principalmente nos campos nativos.

Foram analisados 292 indivíduos, distribuídos em grupos formados por 45 animais Crioulo Lageano (CL) mochos (GI); 43 vacas CL nascidas entre 1982 e 1992 (GII); 42 animais CL nascidos entre 1993 e 1995 (GIII); 37 animais CL nascidos entre 1996 e 1998 (GIV); 43 animais CL nascidos entre 1999 e 2000 (GV); 43 animais da raça Holandesa (GVI) e 39 animais da raça Nelore (GVII). Visando obter amostra representativa das raças Nelore (NEL) e Holandesa (HOL), foram coletadas amostras de diferentes rebanhos do Distrito Federal e de outros Estados de animais PO não aparentados por no mínimo três gerações.

Os componentes sanguíneos (plasma, hemácias e leucócitos) foram separados e armazenados a $-20^{\circ} \mathrm{C}$, para posterior utilização e extração de DNA. Os 43 primers utilizados foram selecionados baseando-se no escrutínio de 120 primers (kits A, B, E, J, K e AB). Para comprovar a repetibilidade das bandas polimórficas, repetiu-se os experimentos, com os primers escolhidos, pelo menos duas vezes. Posteriormente, cada primer selecionado foi amplificado com todas as amostras estudadas das diferentes raças, sendo os resultados gerados para cada raça oriundos do mesmo experimento e corrida eletroforética. Selecionaram-se os primers que apresentavam um bom padrão de amplificação e que geravam pelo menos 4 bandas polimórficas entre os indivíduos.

Após um período de incubação por 5 minutos a $94^{\circ} \mathrm{C}$, para completa desnaturação do DNA molde, foram efetuados 40 ciclos de $1 \mathrm{~min}$ a $94^{\circ} \mathrm{C}, 1 \mathrm{~min}$ a $36^{\circ} \mathrm{C}$ e $2 \mathrm{~min}$ a $72^{\circ} \mathrm{C}$, seguindo-se de $7 \mathrm{~min}$ a $72^{\circ} \mathrm{C}$, para completa extensão dos produtos amplificados. Depois do término da reação o termociclador estava programado para manter a temperatura a $4^{\circ} \mathrm{C}$.

Os produtos de amplificação foram separados por eletroforese, utilizando-se gel de agarose 1,4\% em tampão de corrida contendo Tris, ácido bórico e EDTA (TBE 1X), em voltagem constante de $150 \mathrm{~V}$ até alcançar a distância de $10 \mathrm{~cm}$ do poço de carregamento. Utilizou-se como marcador de massa molecular o ladder de $1 \mathrm{~Kb}$ (Gibco-BRL). A coloração do gel foi feita combrometo de etídio $(0,6 \mathrm{uL} / \mathrm{mL})$ sendo este, em seguida, fotografado sob luz ultravioleta usando o sistema de fotodocumentação Eagle Eye (Stratagene Inc.). Embora várias bandas fossem produzidas por primer, somente aquelas que não davam margem a dúvidas foram consideradas. Os marcadores escolhidos foram computados na forma de uma matriz binária, em que o número zero representou a ausência de fragmento e o número um a presença.

A similaridade genética foi estimada mediante a utilização do coeficiente de Jaccard, o qual faz parte do programa de similaridade de dados qualitativos do NTSYS-pc (Numerical Taxonomy and Multivariate Analysis System), versão 2.0 (Exeter Software, Setauked, N.Y.). O resultado das estimativas aos pares foi expresso na forma de uma matriz de similaridade e, a partir desta, foram determinados agrupamentos pelo Método da Média Aritmética Não Ponderada - UPGMA, conforme Sneath \& Sokal (1973). Os agrupamentos gerados pelo UPGMA foram expressos na forma de um dendrograma, e as ramificações fixadas em um valor médio das distâncias entre dois agrupamentos. Com a soma dos quadrados do comprimento das ramificações pode-se obter a distância entre qualquer par de indivíduos ou populações (Weir, 1996).

As distâncias genéticas entre as raças foram calculadas de acordo com Nei $(1972,1978)$, pelo programa POPGENE (Population Genetic Analysis) versão 1.31 (Yeh et al., 1999). Os dendrogramas gerados a partir das matrizes de distância genética foram determinados por agrupamentos produzidos pelo método de UPGMA. Por meio do programa POPGENE foram gerados índices de diversidade gênica (GST) segundo Nei (1973), os quais são estimados em função das médias das freqüências alélicas para cada grupo. 
A análise da variância molecular (AMOVA) (Excoffier et al., 1992) foi utilizada para investigar a hierarquia da variância usando o programa Arlequin (Schneider et al., 2000). Foram calculadas as porcentagens da variância total que eram atribuídas às diferenças entre e dentro dos grupos. Além da análise dos sete grupos iniciais, foi feita análise conjunta considerando apenas os grupos I a V. Diferenças entre os grupos foram testadas usando o teste Tukey de diferença mínima significativa .

\section{Resultados e Discussão}

Nos 43 primers utilizados para amplificar o DNA de todos os indivíduos estudados, obteve-se um total de 77 bandas polimórficas (5,5 bandas/primer). O número de marcadores polimórficos obtidos por primer varia de acordo com a população estudada. Bailey \& Lear (1994), utilizando RAPD na caracterização de cavalos Árabe e PSI obtiveram uma média de 3,6 marcadores/primer, enquanto que Apostolidis et al. (2000) obtiveram uma média de 10,2 bandas/ primer estudando cavalos gregos.

Nos resultados da análise de variância molecular (AMOVA) pôde-se observar que a maior parte da variância genética total (65,05\%) deveu-se à diferença de indivíduos dentro dos grupos, enquanto que o restante deveu-se a diferenças entre os grupos (Tabela 1). Na análise conjunta dos grupos I a V verificou-se variabilidade genética entre os grupos de $25,28 \%$ e dentro dos grupos de 74,72\%. Os resultados estão de acordo com outros trabalhos com marcadores genéticos (Lara, 1998; Lima et al., 1999; Lougheed et al., 2000; Serrano, 2001).

A distância padrão de Nei (1973) (GST) indica a diferenciação gênica relativa aos grupos estudados

Tabela 1. Análise de variância molecular (AMOVA) dos sete grupos de bovinos estudados a partir de 77 marcadores RAPD.

\begin{tabular}{lrrrr}
\hline Fonte de variação & GL & SQ & QM & \% Total \\
\hline Entre grupos & 6 & Todos os grupos \\
Dentro de grupos & 285 & $2.247,419$ & 207,903 & $34,95^{*}$ \\
\hline \multicolumn{5}{c}{ Crioulo Lageano } \\
Entre grupos & 4 & 583,029 & 145,757 & $25,28^{*}$ \\
Dentro de grupos & 205 & $1.966,661$ & 9,593 & 74,72 \\
\hline
\end{tabular}

*Significativo a 5\% de probabilidade. como um todo, e foi de 0,3314 , sendo este valor condizente com a porcentagem da variabilidade genética existente entre os grupos estudados (34,95\%). Quando este coeficiente foi calculado apenas em relação aos grupos de animais da raça Crioulo Lageano, obteve-se valor de 0,2283. Este resultado era esperado, pois ao analisar apenas a raça Crioulo Lageano, a diferenciação da população como um todo iria diminuir, porque o rebanho é proveniente de um mesmo local e raça. Quando a raça Crioulo Lageano foi agrupada em um único grupo e confrontada com as demais, o valor de GST ficou em 0,3293, o que indica a diferenciação gênica desta raça em relação às raças Nelore e Holandesa. Serrano (2001), ao comparar diferentes raças naturalizadas com as raças Nelore e Holandesa, obteve valores de GST da amostra total estudada de 0,2809. Esta diferença obtida pode ser explicada pela amostragem utilizada em cada um dos estudos. Como foram comparadas cinco raças naturalizadas, originárias da mesma região, este fator contribuiu para a diminuição da diferenciação gênica como um todo.

A diversidade gênica ( $a$ h) (Nei, 1973) de grupos de animais da raça Crioulo Lageano subdivididos de acordo com a idade foi calculada (Tabela 2). Este índice, segundo Weir (1996), é um método alternativo para se medir a variação das populações em estudo, e é uma das medidas mais apropriadas para se medir a variabilidade de populações próximas, que possam ter algum grau de consangüinidade, como é o caso da raça em estudo. Houve diferença significativa somente em relação ao grupo VI (Holandês). Portanto, pode-se concluir que a diversidade gênica vem

Tabela 2. Diversidade gênica dos sete grupos ( $a$ h), de bovinos considerados como populações únicas, obtidas pela média das freqüências alélicas de marcadores RAPD.

\begin{tabular}{lcc}
\hline Grupo $^{(1)}$ & Número de indivíduos & $(a)^{(2)}$ \\
\hline GI & 45 & $0,24904 \mathrm{a}$ \\
GII & 43 & $0,23819 \mathrm{a}$ \\
GIII & 42 & $0,24265 \mathrm{a}$ \\
GIV & 37 & $0,23586 \mathrm{a}$ \\
GV & 43 & $0,24916 \mathrm{a}$ \\
GVI & 43 & $0,12036 \mathrm{~b}$ \\
GVII & 39 & $0,24368 \mathrm{a}$ \\
\hline
\end{tabular}

${ }^{(1) G I: ~ C r i o u l o ~ L a g e a n o ~ M o c h o ; ~ G I I-G V: ~ C r i o u l o ~ L a g e a n o ; ~ G V I: ~ H o l a n-~}$ desa; GVII: Nelore. ${ }^{(2)}$ Médias seguidas da mesma letra não diferem entre si a $5 \%$ de probabilidade pelo teste de Tukey. 
se mantendo ao longo das gerações no núcleo da raça Crioulo Lageano e que os alelos de interesse não estão sendo perdidos e a variabilidade do rebanho não alcançou níveis críticos.

A raça Holandesa apresentou menor diversidade gênica $(0,1204)$ do que a raça Nelore $(0,2437)$ e o maior índice foi o da raça Crioulo Lageano $(0,3154)$ (Tabela 3). A menor diversidade da raça Holandesa e da Nelore já era esperada e assemelha-se aos resultados obtidos por Egito (1995), Lara (1998) e Serrano (2001). O índice de diversidade gênica observado por Serrano (2001) na raça Crioulo Lageano foi inferior $(0,2409)$ ao obtido no presente trabalho, o que pode ser explicado pelo número de indivíduos utilizados em cada um desses estudos (48 versus 210). Na análise da população de animais mochos, verificou-se que a diversidade gênica deste grupo de animais é menor $(0,2490)$ do que a dos demais grupos da raça Crioulo Lageano $(0,313)$. Este menor valor em relação aos outros Crioulos pode estar relacionado ao fato de ter havido maior controle deste grupo por parte do criador, sendo que estes, teoricamente, são descendentes de um único touro. A comparação dos valores obtidos em relação às raças Nelore e Crioulo Lageano com o valor obtido da raça Holandesa sugere que muitos trabalhos de melhoramento genético ainda podem ser realizados naquelas duas raças. Este ponto também foi levantado por Lara (1998) e Serrano (2001).

As distâncias genéticas padrão (Dp) foram, em geral, superiores às distâncias corrigidas (Dc) (Tabela 4). Como foram condizentes, os resultados comentados basear-se-ão nas distâncias genéticas obtidas pelo índice de Nei (1972). A menor distância genética foi observada entre os grupos IV e V $(0,0733)$, aos quais pertencem os animais mais novos da raça Crioulo Lageano do núcleo de conservação. Este resultado pode indicar que está havendo homogeneização desta população que poderá levar

Tabela 3. Diversidade gênica das raças de bovinos ( $a$ h), de acordo com Nei (1973), utilizando-se o programa POPGENE.

\begin{tabular}{lcc}
\hline Raça & Número de indivíduos & $(a \mathrm{~h})$ \\
\hline Crioulo Lageano (I a V) & 210 & 0,3154 \\
Holandesa (VI) & 43 & 0,1204 \\
Nelore (VII) & 39 & 0,2437 \\
\hline
\end{tabular}

à diminuição da variabilidade genética. O grupo III (animais nascidos de 1993 a 1996) foi o que ficou mais distante geneticamente do grupo V (1999 a 2000). Teoricamente estes grupos devem ser os mais próximos, pois o grupo $\mathrm{V}$ poderia ter animais que descenderiam do grupo III. Além disso, este grupo é o mais distante, geneticamente, dos demais grupos da raça Crioulo Lageano e também do Nelore (GVII). O grupo II, que representa os animais mais idosos do rebanho Crioulo Lageano, foi o que apresentou as menores distâncias genéticas, tanto em relação à raça Nelore $(0,1934)$ quanto em relação à raça Holandesa $(0,1222)$. Tal fato pode ser explicado pela presença de animais neste grupo que possuem maior miscigenação com as raças comparadas.

Pelo dendrograma gerado pelo método de UPGMA pode-se observar a menor distância genética entre os grupos IV e V, os quais reunem-se em um mesmo agrupamento, demonstrando sua maior proximidade (Figura 1). Os grupos II e III reunem-se em agrupamento distinto dos demais, sendo o grupo III o mais distante em relação aos grupos da raça Crioulo Lageano. Os grupos compostos por animais taurinos reunem-se em um agrupamento separado do Nelore (Bos indicus). Serrano (2001) encontrou resultados similares ao comparar cinco raças nativas (Bos taurus) com a Nelore (Bos indicus).

A comparação dos animais Crioulo Lageano mochos e os demais foi realizada mediante o agrupamento dos grupos II a V (Tabela 5). Os valores foram menores em relação às populações da mesma raça, indicando a grande similaridade existente entre elas. Entre os grupos da raça Crioulo Lageano, o grupo

Tabela 4. Distância genética entre sete grupos de bovinos estimados pelo método de Nei (1972 - abaixo da diagonal; e 1978 - a distância corrigida), a partir de dados obtidos pela técnica de RAPD, utilizando-se o programa POPGENE(1).

\begin{tabular}{|c|c|c|c|c|c|c|c|}
\hline Grupos & GI & GII & GIII & GIV & GV & GVI & GVII \\
\hline$\overline{\mathrm{GI}}$ & ------ & 0,1015 & 0,1625 & 0,0732 & 0,1064 & 0,1832 & 0,2281 \\
\hline GII & 0,1052 & ------- & 0,1439 & 0,1173 & 0,1248 & 0,1195 & 0,1894 \\
\hline GIII & 0,1663 & 0,1477 & ------- & 0,1542 & 0,1778 & 0,2298 & 0,2888 \\
\hline GIV & 0,0772 & 0,1212 & 0,1583 & ------- & 0,0692 & 0,2500 & 0,2356 \\
\hline GV & 0,1102 & 0,1286 & 0,1817 & 0,0733 & ------- & 0,2233 & 0,2665 \\
\hline GVI & 0,1858 & 0,1222 & 0,2325 & 0,2529 & 0,2260 & ------- & 0,3718 \\
\hline GVII & 0,2321 & 0,1934 & 0,2929 & 0,2398 & 0,2706 & 0,3747 & ------- \\
\hline
\end{tabular}

Pesq. agropec. bras., Brasília, v. 38, n. 10, p. 1157-1164, out. 2003 
mocho é o que apresenta as maiores distâncias genéticas em relação às raças Nelore e Holandesa. Ambos os grupos estão mais próximos geneticamente da raça Holandesa do que da raça Nelore.

Os maiores valores de distância genética foram observados na comparação das raças Nelore e Holandesa (0,3747). Lara (1998) obteve valores de Dp inferiores $(0,3256)$ aos observados neste trabalho, o que pode ser justificado pela utilização de polimorfismos protéicos. Os valores obtidos por Serrano (2001), nesta comparação, foram superiores $(0,4260)$ ao observado. Isto deve ter ocorrido por causa do número de indivíduos e marcadores RAPD utilizados nesses experimentos.

No dendrograma gerado a partir da matriz de distância genética padrão (Figura 2), as raças taurinas

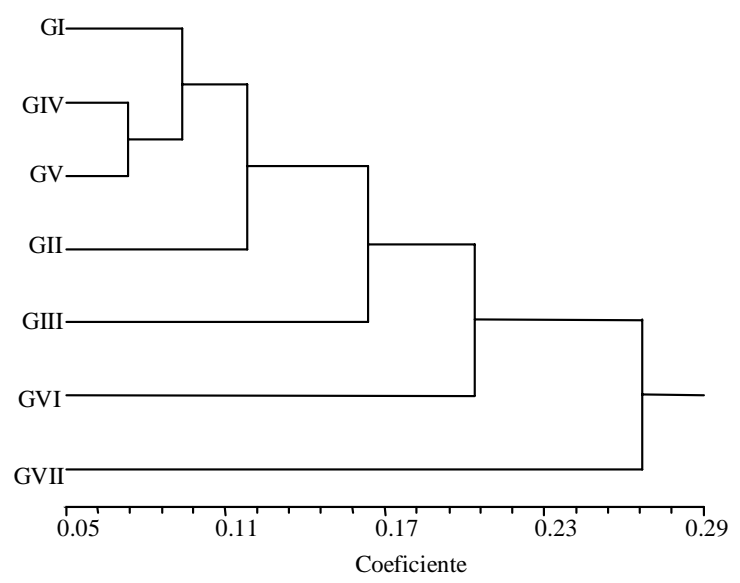

Figura 1. Dendrograma gerado pelo método de UPGMA, para as distâncias padronizadas entre os grupos Crioulo Lageano Mocho (G1), Crioulo Lageano (GII - GV), Holandesa (GVI) e Nelore (GVII), obtidas pelo POPGENE (Nei, 1972).

Tabela 5. Índices de distâncias genéticas, observadas entre os animais da raça Crioulo Lageano (CL), Crioulo Lageano mocho e das raças Holandesa (Hol) e Nelore (Nel), estimados pelo método de Nei (1972 - abaixo da diagonal; e 1978 - acima da diagonal), a partir de 77 marcadores RAPD.

\begin{tabular}{lcccc}
\hline Raça & CL mocho & CL & Hol & Nel \\
\hline CL mocho & - & 0,0628 & 0,1832 & 0,2281 \\
CL & 0,0653 & - & 0,1539 & 0,1958 \\
Hol & 0,1858 & 0,1554 & - & 0,6895 \\
Nel & 0,2321 & 0,1986 & 0,3747 & - \\
\hline
\end{tabular}

Pesq. agropec. bras., Brasília, v. 38, n. 10, p. 1157-1164, out. 2003 reuniram-se em um agrupamento separado da raça Nelore. A menor divergência genética foi entre as populações de Crioulo Lageano, que também estão mais próximas da raça Holandesa do que da raça Nelore. Esta distribuição no dendrograma também foi observada por Serrano (2001).

A matriz de similaridade genética entre todos os indivíduos gerada pelo índice de Jaccard foi utilizada para gerar, pelo método UPGMA, um dendrograma com todas as amostras utilizadas. Foi possível observar a distinção do grupo VII (Nelore, Bos indicus) dos demais (Crioulo Lageano e Holandês, ambas Bos taurus). Este resultado já era esperado em razão da origem das raças; a Nelore foi incluída como outgroup e para verificar a possível introgressão de genes zebuínos na população crioula. Os grupos I, IV e V formaram um agrupamento separado, demonstrando sua maior similaridade, assim como o grupo II e a raça Holandesa agruparam-se juntos. Estes dados estão de acordo com os valores obtidos pela distância genética de Nei (Tabela 5). O grupo II foi o que apresentou menor distância genética em relação à raça Holandesa.

O grupo III agrupou-se de maneira distinta dos demais grupos de sua raça e da raça Holandesa, e o grupo dos Crioulos Lageanos apresentou-se mais homogêneo. A hipótese preconizada é que este grupo tenha recebido genes de outra população/raça, o que o diferenciou dos demais. Spritze (2001), ao estudarem o peso ao nascer de bezerras Crioulo

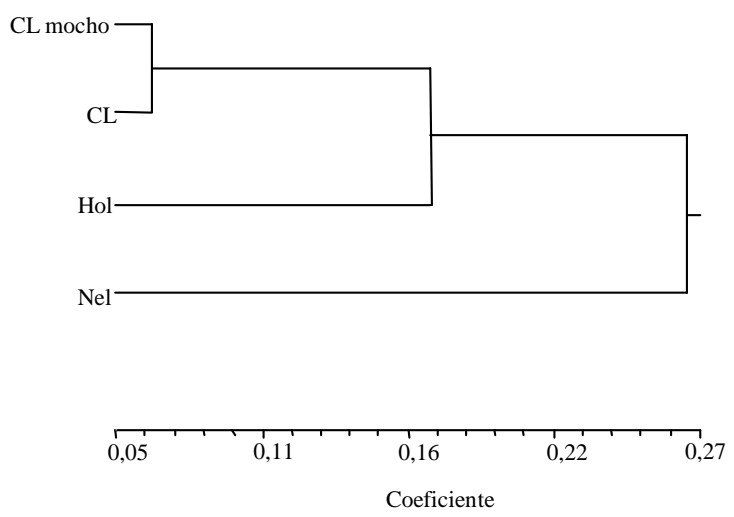

Figura 2. Dendrograma gerado pelo método de UPGMA para distâncias genéticas obtidas pelo método de Nei (1972), entre as raças bovinas Crioulo Lageano (CL), Holandesa (Hol) e Nelore (Nel). 
Lageano nos anos de 1982 e 1997, observaram que nos anos de 1992 e 1993 ocorreu aumento significativo no peso. Este aumento não se manteve, e nos anos seguintes a média de peso ao nascer novamente diminuiu. $\mathrm{O}$ aumento verificado naqueles dois anos pode ser efeito da heterose obtida por meio do cruzamento com outras raças.

Não se pode descartar ainda a hipótese de que este distanciamento do grupo III possa ser solucionado com o aumento no número de marcadores utilizados. Assim sendo, sugere-se que outros estudos sejam realizados utilizando-se outras técnicas, como microssatélites, de forma a confirmar os resultados obtidos no presente trabalho. Sugere-se ainda que a raça Charolesa seja utilizada nos próximos trabalhos realizados com esta raça.

\section{Conclusões}

1. A diversidade gênica da raça Crioulo Lageano é maior do que a observada na amostra das raças Nelore e Holandesa.

2. Não houve perda da diversidade gênica ao longo das gerações no Núcleo de Conservação da raça Crioulo Lageano.

3. A maior similaridade genética nos animais mais novos pode influenciar negativamente a variabilidade genética e a conservação da raça Crioulo Lageano.

\section{Referências}

APOSTOLIDIS, A. P.; MAMURIS, Z.; KARKAVELIA, E.; ALIFAKIOTIS, T. Comparison of Greek breeds of horses using RAPD markers. Journal of Animal Breeding and Genetics, Berlin, v. 118, p. 47-56, 2000.

ARAÚJO, R. V. Os jesuítas dos 7 povos. Porto Alegre: La Salle, 1990. 467 p.

BAILEY, E.; LEAR, T. L. Comparison of Thoroughbred and Arabian horses using RAPD markers. Animal Genetics, Oxford, v. 25, n. 1, p. 105-108, 1994. Supplement.

EGITO, A. A. de. Uso de marcadores RAPD na identificação e caracterização genética de raças bovinas existentes no Brasil. 1995. 95 f. Dissertação (Mestrado em Genética) - Universidade de São Paulo, Ribeirão Preto, 1995.
EGITO, A. A. de; AlbuQUerQue, M. S.; MARIANTE, A. da S. Caracterização genética de raças naturalizadas. In: SIMPÓSIO DE RECURSOS GENÉTICOS PARA AMÉRICA LATINA E CARIBE, 3., 2001, Londrina. Anais... Londrina: Instituto Agronômico do Paraná, 2001. p. 121-126.

EXCOFFIER, L.; SMOUSE, P. E.; QUATTRO, J. M. Analysis of molecular variance inferred from metric distances among DNA haplotypes: application to human mitochondrial DNA restriction data. Genetics, Pittsburgh, v. 131, p. 479-491, 1992.

LARA, M. A. C. Variabilidade genética em bovinos e bubalinos através de polimorfismos protéicos: análise populacional e suas implicações no melhoramento. 1998. 215 f. Tese (Doutorado em Genética) - Faculdade de Medicina de Ribeirão Preto, Ribeirão Preto, 1998.

LIMA, L. H. C.; CAMPOS, L.; MORETZSOHN, M. de C.; NAVIA, D.; SILVA. O. L. R.; OLIVEIRA, M. R. V. de. Populações do complexo Bemisia tabaci (Gennadius) através de RAPD-PCR: análise da diversidade genética. Brasília: Embrapa-Cenargen, 1999. p. 1-5. (Boletim de Pesquisa e Desenvolvimento, 22).

LIMA, M. L. P.; BONILHA NETO, L. M.; RAZOOK, A. G. O gado Caracu. Revista dos Criadores, São Paulo, v. 59, p. 28-30, 1990.

LOUGHEED, S. C.; GIBBS, K. A.; WEATHERHEAD, P. J. A comparison of RAPD versus microsatellite NDA markers in population studies of the Massasauga Rattlesnake. Journal of Heredity, Oxford, v. 91, p. 458463, 2000.

MARIANTE, A. da S.; CAVALCANTE, N. Animais do descobrimento: raças domésticas da história do Brasil. Brasília: Embrapa-Cenargen, 2000. 232 p.

MARIANTE, A. da S.; TROVO, J. B. F. The Brazilian genetic resources conservation programme. Revista Brasileira de Genética, Ribeirão Preto, v. 12, n. 3, p. 241256, 1989.

MORAES, A.; MARASCHIN, G. E.; NABINGER, C. Pastagens nos ecossistemas de clima subtropical: pesquisas para o desenvolvimento sustentável. In: SIMPÓSIO SOBRE PASTAGENS NOS ECOSSISTEMAS BRASILEIROS, 1995, Brasília. Anais... Brasília: Sociedade Brasileira de Zootecnia, 1995. p. 147-200.

NEI, M. Analysis of gene diversity in subdivided populations. Proceedings of the National Academy of Sciences of the United States of America, Washington, v. 70, p. 3321-3323, 1973. 
NEI, M. Estimation of average heterozygosity and genetic distance from a small number of individuals. Genetics, Pittsburgh, v. 89, p. 583-590, 1978.

NEI, M. Genetic distance between populations. American Naturalist, Chicago, v. 106, p. 238-292, 1972.

PAYNE, W. Y. A. Cattle production in the tropics. London: Longman, 1970. v. 1.

PRIMO, A. T. Os bovinos ibéricos nas Américas. In: REUNIÃO ANUAL DA SOCIEDADE BRASILEIRA DE ZOOTECNIA, 1993, Rio de Janeiro. Anais.... Rio de Janeiro: Sociedade Brasileira de Zootecnia, 1993. p. 183-199.

SCHNEIDER S.; ROESSLI D.; EXCOFFIER L. Arlequin: version 2.000: a software for population genetics data analysis. Geneva: University of Geneva, 2000. $111 \mathrm{p}$.

SERRANO, G. M. S. Uso de marcadores moleculares RAPD na caracterização genética das raças bovinas nativas brasileiras. 2001. 87 f. Dissertação (Mestrado em Ciências Agrárias) - Universidade de Brasília, Brasília, 2001.

SNEATH, P. H. A.; SOKAL, R. R. Numerical taxonomy: the principles and practice of numerical classification. San Francisco: W. H. Freeman. 1973. 573 p.

SPRITZE, A. Uso de marcadores moleculares RAPD na caracterização genética da raça bovina Crioulo Lageano. 2001. 67 f. Dissertação (Mestrado em Ciências Agrárias) - Universidade de Brasília, Brasília, 2001.

WEIR, B. S. Genetic data analysis II: methods for discrete population genetics data. Sunderland: Sinauer Associates, 1996. 445 p.

YEH, F. C.; YANG, R.; BOYLE, T. POPGENE: Microsoft Window-based freeware for population genetic analysis: version 1.3: manual. Edmonton: University of Alberta, 1999. $29 \mathrm{p}$. 